\title{
Thermal behavior study of the mold surface in HPDC process by infrared thermography and comparison with simulation
}

\author{
By S. TAVAKOLI ${ }^{* *},{ }^{*}$, I. RANC ${ }^{*}$, D. WAGNER * \\ * LEME, Paris Ouest Nanterre La Défense University, 92410 Ville d’Avray, France, dwagner@u- \\ paris10.fr, isabelle.ranc@u-paris10.fr \\ ** RENAULT S.A.S, Mechanical \& Production Engineering Department, Rough Parts Departement, \\ 92508, Rueil Malmaison, France, shahab.tavakoli@renault.com
}

\begin{abstract}
The temperature fields on the die surface measured by an infrared camera during High Pressure Die Casting process. It is compared to the simulation which has already been adjusted by 8 thermocouples. The directional emissivity of the mold surface is measured in the spectral range $[7.5-13 \mu \mathrm{m}]$ between $63-174^{\circ} \mathrm{C}$. We obtained an almost uniform emissivity from normal direction to the surface up to $60^{\circ}$. The surface condition is a key point to achieve a reliable temperature field. Similar areas in the temperature fields are identified between experiments and simulation although the measurement conditions are particularly difficult in the foundry environment.
\end{abstract}

\section{Introduction}

Nowadays, the use of light alloys such as Aluminum, Zinc and Copper in automotive, aerospace and trail industry is growing significantly compared to other alloys. The HPDC (High Pressure Die Casting) is the most appropriate process for these alloys to make very thin castings with complex shapes. This process involves three main phases: molten metal injection under a high pressure (900 bar) in the mold cavity and casting solidification, -mold opening and solidified casting extraction by a robot, -mold cooling by a die-lubricant spray and blowing [1]. This study concerns the AISi9Cu3Fe alloy which is commonly used for casting and a high chromium steel material for the die. The thermal behavior knowledge of the mold cavity is a key point in order to achieve castings conformity and an agreed production rate. In this paper, the temperature on gearbox housing mold surface in running mode has been followed by an infrared camera in the Renault foundry. To achieve a minimum error for this temperature monitoring and to take into account the

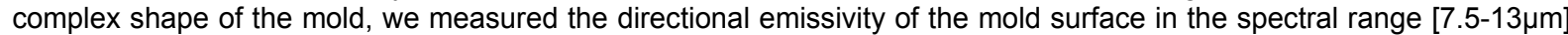
of the camera, between $63^{\circ} \mathrm{C}$ and $174^{\circ} \mathrm{C}$, for two different surface conditions. At the end of this article, a comparison study between the measured temperature fields and the simulated ones by ProCAST software is shown. The simulation has already been adjusted to measured temperatures in the mold cavity during the process, obtained by a 8 thermocouples instrumentation. This provided us the Heat Transfer Coefficients values used in the simulation.

\section{Experiments in production site}

In the first test series, the opened mold surface temperature is recorded by the infrared thermal camera for 20 part

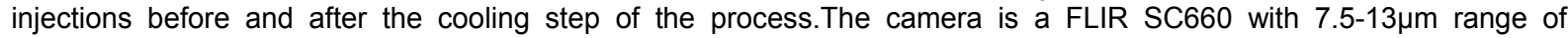
wavelength, equipped with an uncooled microbolometer, $640 \times 480$ pixels of resolution and automatic calibration. The acquisition frequency is $1 \mathrm{~Hz}$. The camera is located at $90^{\circ}$ relative to the machine axis (1), Figure 1). The second test series registered the temperature for 31 part injections with the camera at $45^{\circ}$ to the machine axis (2), Figure 1). This last position can cover the maximum area of the mold surface.

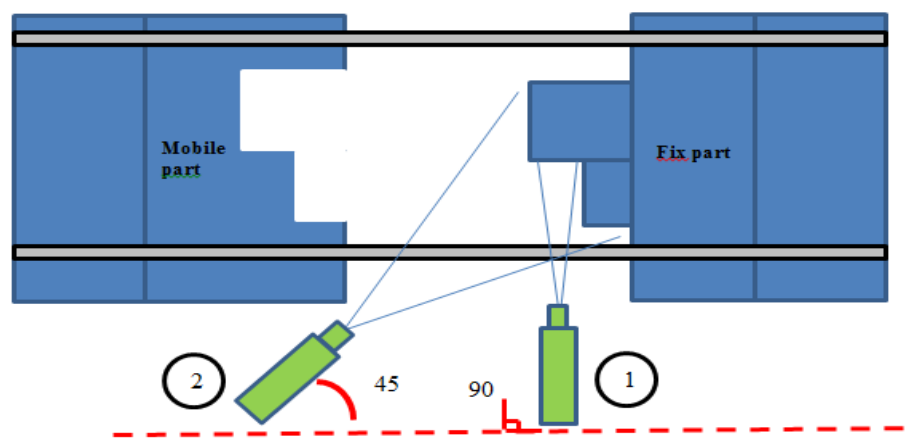

Figure 1: Measuring the die surface temperature in two different positions 


\section{Results}

In IR temperature measurements, it is very important to have a good knowledge of the emissivity. In the spectral range of the camera $(7,5-13 \mu \mathrm{m})$, the influence of accuracy of $5 \%$ on emissivity is about $8{ }^{\circ} \mathrm{C}$ for the $7.5 \mu \mathrm{m}$ and $12^{\circ} \mathrm{C}$ for $13 \mu \mathrm{m}$. It can reach $23^{\circ} \mathrm{C}$ if the accuracy is as bad as $10 \%$. So we measured the emissivity of the die surface in the temperature range $\left(63^{\circ} \mathrm{C}-174^{\circ} \mathrm{C}\right)$ of the process cooling step, from normal direction to the surface up to $60^{\circ}$ and for two different surface conditions, taking into account the metal oxidation which notably modifies emissivity [2]. Two typical zones of the mold surface have been chosen: damaged zone by thermal fatigue (for a mold at the end of its lifetime) or non-damaged zone. The samples have been cut from a die at the end of its lifetime (Figure 2).

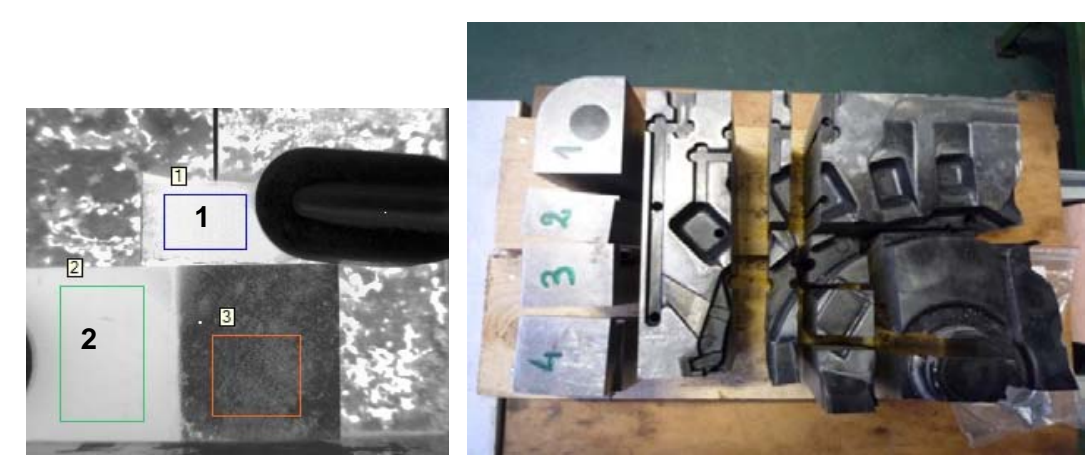

A

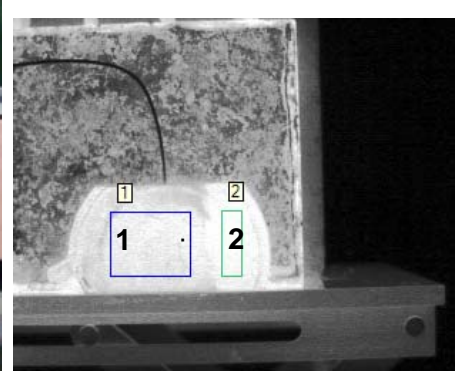

B

Figure 2 : Two specimens taken from the die surface for the emissivity measuring, A: non- damaged and B: damaged

$$
\text { surface }
$$

\subsection{Emissivity measurement}

The Figure 3 shows the experimental device carried out to measure emissivity. On each specimen, we painted a black area to use it as a black body (Figure 2 thermography image A area 2). The specimens are heated by Joule effect and conduction: heating rods are placed in copper plates put into contact with the specimen. Its temperature is controlled by a thermocouple. The whole system is protected from the environmental radiation by a protection box. The camera is in front of the specimens with a sighting angle (Figure 3) from 0 to (normal) to $60^{\circ}$. The distance between the camera lens and the specimen surface is 0.4 meter.

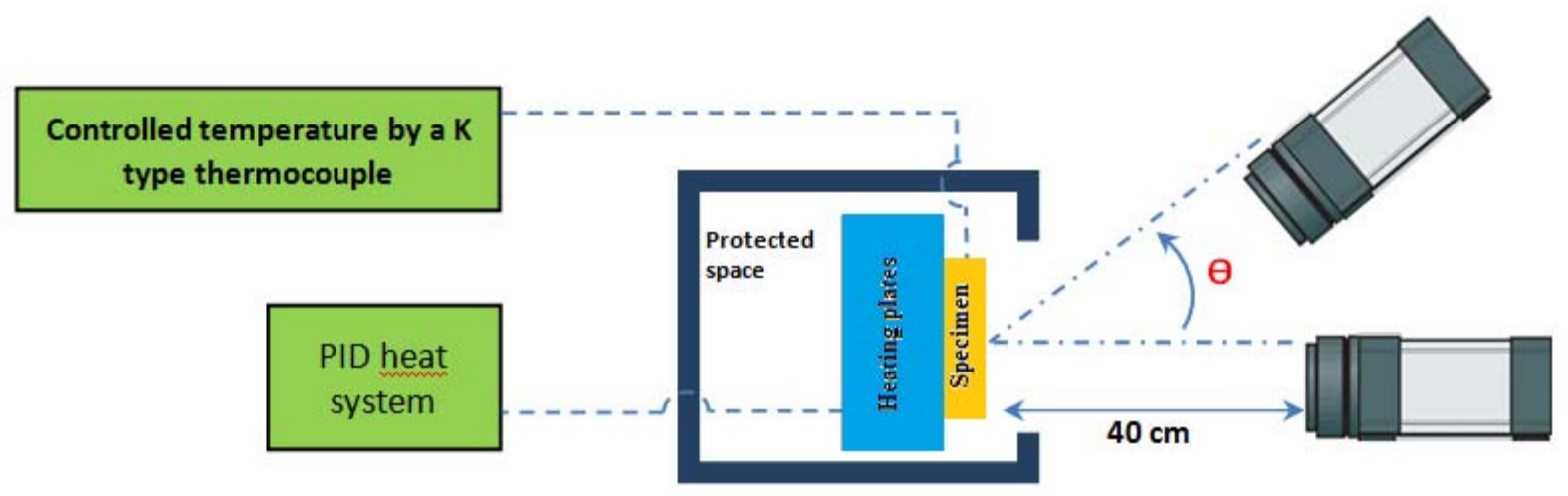

Figure 3 : Measurement device for the angular emissivity

The values of the temperature $\mathrm{T}$ given by the thermocouple are the same than the ones we obtained on the thermographies by choosing $\varepsilon=0.93$ for the black body area. This value corresponds to the black paint emissivity. 
Then we have obtained the specimen emissivity following the relation:

$$
\begin{aligned}
\int_{7.5}^{13} L_{\lambda}(T) \cdot d \lambda=\int_{7.5}^{13} \varepsilon_{\lambda} L_{\lambda}^{\circ}(T) \cdot d \lambda & \cong<\varepsilon_{7.5-13, \theta}>\int_{7.5}^{13} L_{\lambda}^{\circ}(T) \cdot d \lambda \\
& =\int_{7.5}^{13} L_{\lambda}^{\circ}\left(T_{\text {lum }}\right) \cdot d \lambda \\
<\varepsilon_{7.5-13, \theta}> & =\frac{\int_{7.5}^{13} L_{\lambda}^{\circ}\left(T_{\text {lum }}\right) \cdot d \lambda}{\int_{7.5}^{13} L_{\lambda}^{\circ}(T) \cdot d \lambda}
\end{aligned}
$$

where the temperature $T_{\text {lum }}$ is the specimen temperature obtained in the non-black areas of the infrared picture, assuming an emissivity of $0.93(\varepsilon=0.93)$ and $L_{\lambda}{ }^{\circ}$ is the luminance of the black body. The values of the damaged fatigue zone (0.92-0.93) are close to the black body emissivity. The emissivities of the non-damaged areas are shown on Figure 4 for four temperature levels. These obtained values are in the range of $0.12-0.3$. We show on the same figure the emissivities of a low oxidized stainless steel given by Ané et al [2]. As results, whatever the surface conditions, the emissivity is not influenced by the sighting angle.

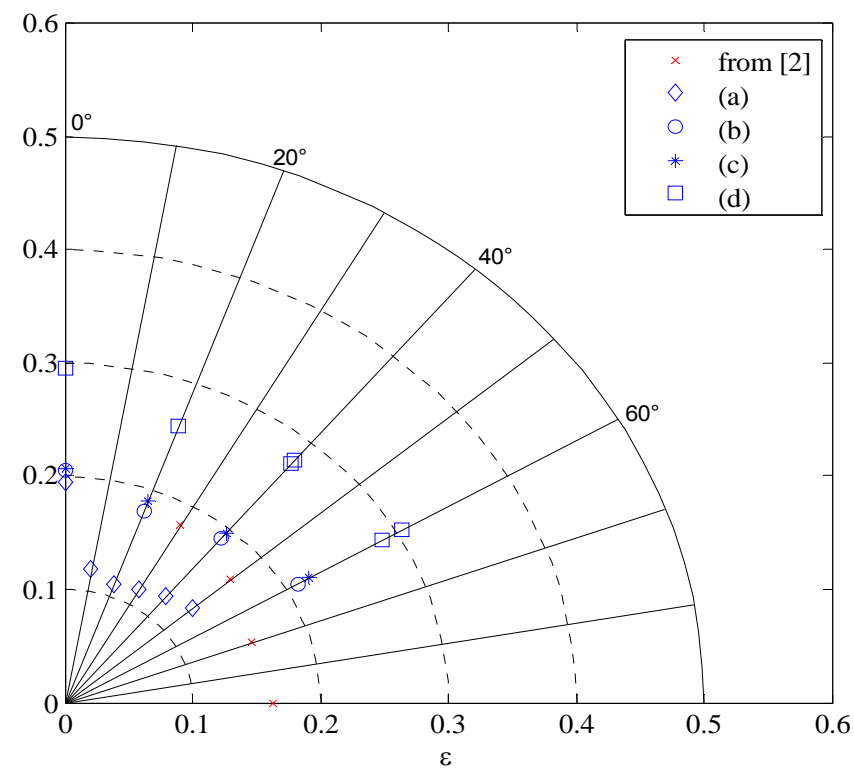

Figure 4 : Emissivity of non-damaged specimen at different temperatures (a) : $63^{\circ} \mathrm{C}(\mathrm{b}): 119^{\circ} \mathrm{C}(\mathrm{c}): 147^{\circ} \mathrm{C}(\mathrm{d}): 174^{\circ} \mathrm{C}$,

compared to stainless steel emissivities given by Ané et al [2]

\subsection{Uncertainty estimation on the emissivity determination}

To estimate the global accuracy of the emissivity determination, we have to take into account the accuracy of the temperature measurement given by our camera which is due to two factors: the environment and the surface nonuniformity.On the temperature error due to the environment, the internal processing of the camera takes into account the reflected emission on the surface of the object from the environment and the thickness of atmosphere between the studied surface and the lens (see Figure 5). 


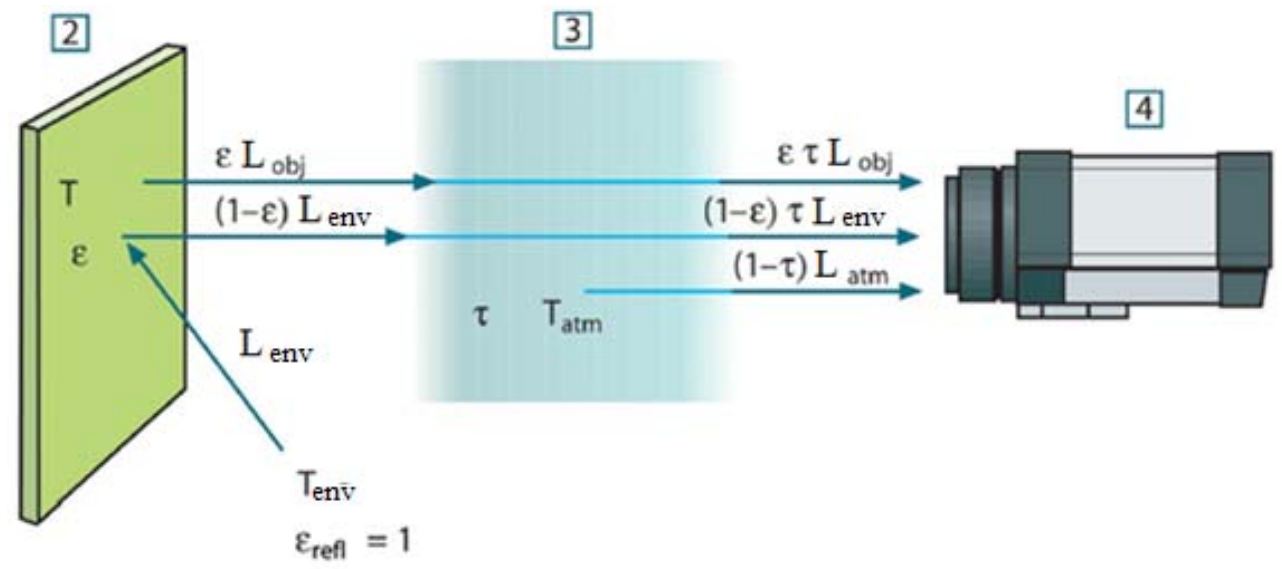

Figure 5 : A schematic representation of the general thermography measurement. 1: Environment; 2: Object; 3:

Atmosphere; 4: camera [3]

The total radiation received can be shown as follows :

$$
L_{\text {tot }}=\tau<\varepsilon_{7.5-13}>\int_{7.5}^{13} L_{\lambda}^{\circ}(T) d \lambda+\tau\left(1-<\varepsilon_{7.5-13}>\right) L_{\text {env }}+(1-\tau) L_{a t m}
$$

where:

- The first term is the emitted radiance from the object at given temperature $(T)$ transmitted by the atmosphere and $T$ is the transmission of atmosphere in front of the camera in the range $7.5-13 \mu \mathrm{m}$

- The second term is the reflected emission from the environment $L_{e n v}$

- The last one is due to emission of the atmosphere $L_{a t m}$

The minimum specimen temperature is $63^{\circ} \mathrm{C}$ and the camera was placed at a short distance $(0.4 \mathrm{~m}$ see Figure 3$)$ from the specimen in order to make negligible the term $L_{\text {env }}$ and $L_{\text {atm. }}$. The protection box helps also to reduce these two effects. Meca Meca has also shown [4] that the infrared temperature measurement has a low sensitivity to the accuracy of the ambient and atmosphere temperatures. On the temperature error due to the surface non-uniformity, we calculated $7 \%$ accuracy on the emissivity at $63^{\circ} \mathrm{C}$ taking a luminance temperature inhomogeneity up to $6^{\circ} \mathrm{C}$ on the surface of specimen (see Figure 6). At $119^{\circ} \mathrm{C}$ and $147^{\circ} \mathrm{C}$, we calculated $3 \%$ accuracy, observing a maximum luminance temperature difference of $5^{\circ} \mathrm{C}$. At $174^{\circ} \mathrm{C}$, the accuracy is $2 \%$

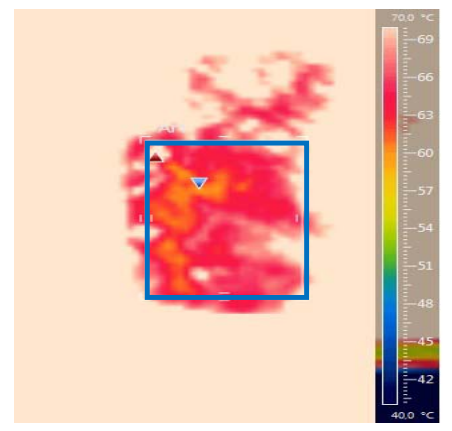

Figure 6 : an infrared image showing non-uniformity of the temperature; the image is obtained with $\varepsilon=0.93$ 
According to the technical specifications of the FLIR SC660 camera, the global measurement accuracy is $2 \%$ in the range of $0-500^{\circ} \mathrm{C}\left( \pm 3.5^{\circ} \mathrm{C}\right.$ for $174^{\circ} \mathrm{C}$ and $1.3^{\circ} \mathrm{C}$ for $\left.63^{\circ} \mathrm{C}\right)$. This value leads to an accuracy estimation on emissivity lower than the one we calculated due to the surface non-uniformity. Actually, we can conclude that the emissivity determination at the lower temperature $\left(63^{\circ} \mathrm{C}\right)$ is less accurate than the other ones. Obviously this is due to the lower signals observed at low temperature.

\subsection{Comparison between simulated and infrared temperature fields on the mold surface}

Seen the low variation of the measured directional emissivity, we didn't take into account the angle between the mold surface and camera to evaluate the temperature. Only two emissivity values, related to the black body (0.93) and the non-damaged areas (0.2-0.3) have been considered, the minimum mold surface temperature being around $100^{\circ} \mathrm{C}$. The temperature fields comparison between the simulation and the Infra-Red camera before(Figure 7) and after (Figure 8 ) the cooling sequence shows a good correlation for the entire die surface for the camera located at $45^{\circ}$. In this example, the emissivity is 0.93 for the whole mold surface. Similar areas in temperature fields are identified by the same colors arrows.
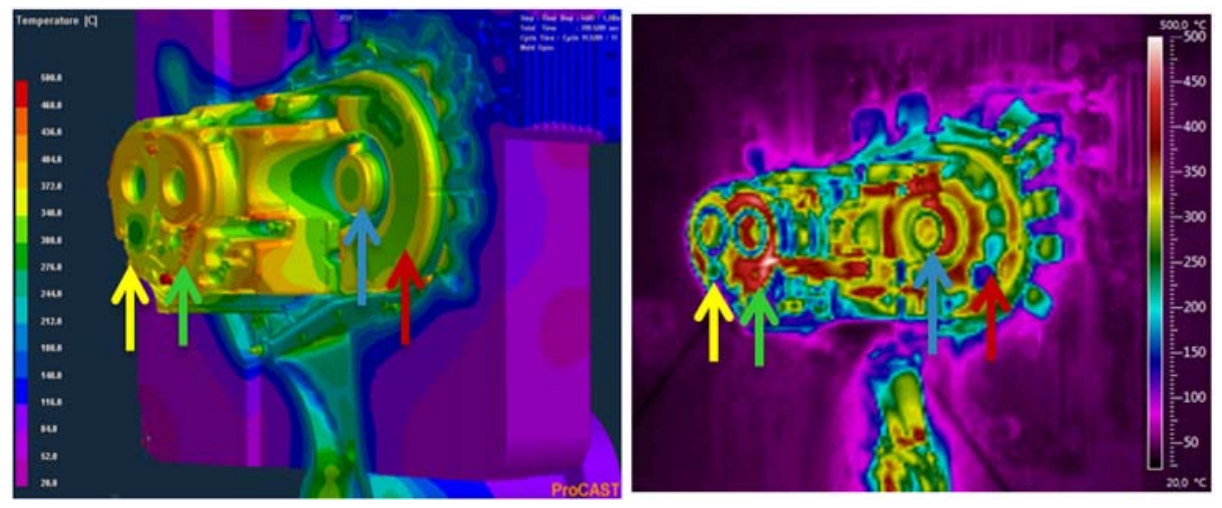

Figure 7: Simulation VS thermal imaging correlation taken by Infra-Red camera FLIR 660 before the cooling sequence
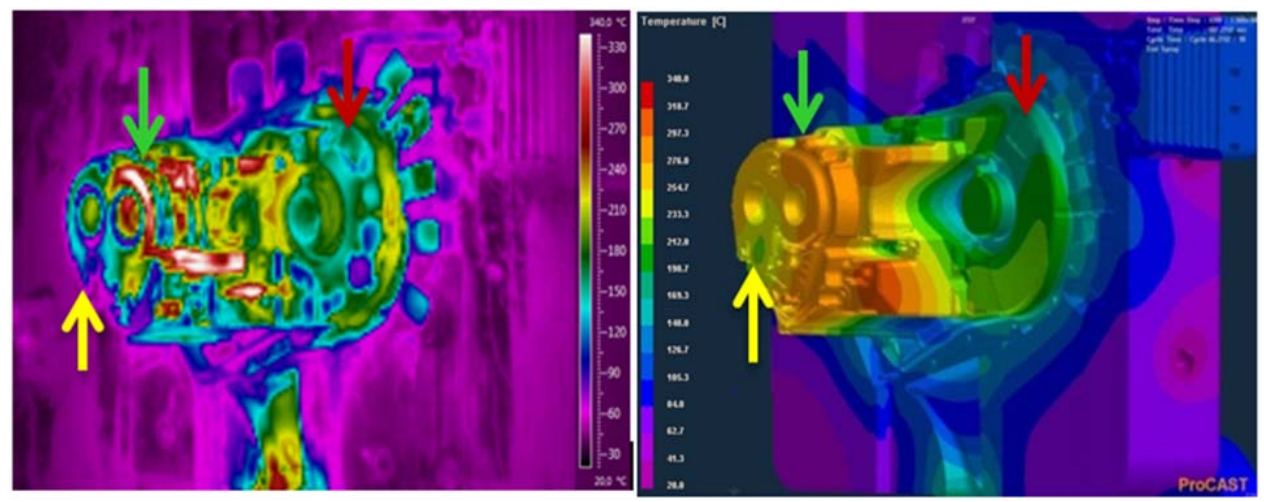

Figure 8: Simulation VS thermal imaging correlation taken by Infra-Red camera FLIR 660 after the cooling sequence

\section{Conclusion}

- $\quad$ In this study, the temperature fields on the die surface are measured by an infra-red camera during the die opening time for a High Pressure Die Casting process

- $\quad$ Elsewhere, the directional emissivity of the mold surface has been measured in the spectral range $7.5-13 \mu \mathrm{m}$ between $63^{\circ} \mathrm{C}$ and $174^{\circ} \mathrm{C}$ on a damaged and non-damaged of the mold surface

- The emissivity is weakly influenced by the direction of the infra-red measuring 
- The temperature fields identified between experiment and the simulation give the similar results which means that ProCAST software simulation is valuable

\section{REFERENCES}

[1] A. Long, D. Thornhill, C. Armstrong, D. Watson, Determination of the heat transfer coefficient at the metal-die interface for high pressure die cast AISi9Cu3Fe, Elsevier, Applied Thermal Engineering. 2011. 31(2011) 39964000

[2] J.M Ané, M. Huetz-Aubert, Int. J. Thermophys., 7:1191, 1986

[3] Utilization Manuel, FLIR, Oct 2010, French, publ. No. 1558553 Rev. 3483

[4] Francisco Javier Meca Meca, Francisco Javier Rodríguez Sanchez, Pedro Martín Sanchez, Calculation and optimization of the maximum uncertainty in infrared temperature measurements taken in conditions of high uncertainty in the emissivity and environment radiation values, Infrared Physics \& Technology Journal, Volume 43, Issue 6, December 2002, Pages 367-375 